\title{
A MORRIS-SOBOL TWO-LAYER PROGRESSIVE MODEL FOR SENSITIVITY ANALYSIS OF PARAMETERS IN RAINFALL THRESHOLD CALCULATION OF FLASH FLOOD
}

\author{
Wenlin $\mathrm{YUAN}^{1}$, Qianyu $\mathrm{GAO}^{1 *}$, Fang $\mathrm{WAN}^{2,4 * *}$, Xiaolei $\mathrm{ZHANG}^{3}$ and Fuqiang $\mathrm{WANG}^{2,4}$
}

${ }^{1}$ School of Water Conservancy and Environment, Zhengzhou University, Zhengzhou 450001, China

${ }^{2}$ School of Water Conservancy, North China University of Water Resources and Electric Power, Zhengzhou 450045, China

${ }^{3}$ China Institute of Water Resources and Hydropower Research, Beijing 100038, China

${ }^{4}$ Collaborative Innovation Center of Water Resources Efficient Utilization and Support Engineering, Zhengzhou 450046, China

*Corresponding authors: qianyugaoxin@163.com;**wanxf1023@163.com

(Received May 2018; accepted July 2018)

Key words: flash flood, rainfall threshold, parameter sensitivity analysis, Morris-Sobol two-layer progressive model, water level-discharge inversion method

\begin{abstract}
As one of the most hazardous natural events, flash flood is frequently responsible for loss of life and severe damage to infrastructure and public health. The Rainfall Threshold (RT) is the main warning index of flash flood that is used in China. However, the amount of parameters in RT calculation is significantly large, and the determination of some parameter values is affected by subjective factors substantially. In this paper, a Morris-Sobol Two-layer Progressive Model (M-STPM) is established to identify sensitive parameters in RT calculation. Firstly, the Morris screening method is applied to qualitatively analyse the sensitivity of parameters, while the insensitive parameters are filtered. Then the Sobol method is employed to quantify the sensitivity. The sensitivity of parameters in RT calculation is determined through a case study in Duli Village of Anyang County in Henan Province. The results indicate that mean of 1 -h annual maximum point rainfall is the most influential parameter. It is found that the parameters in water level-discharge relation calculation have a large influence on the RT, which shows that the proposed model can provide a reference for determining the value of parameters and can lay a theoretical foundation for further error analysis in RT calculation.
\end{abstract}

Palabras clave: inundación repentina, umbral de precipitación, parámetro de sensibilidad, modelo progresivo Morris-Sobol de dos capas, método inverso del nivel de descarga de agua

\section{RESUMEN}

Las inundaciones repentinas, uno de los eventos naturales más peligrosos, son con frecuencia responsables de la pérdida de vidas humanas y de daños a la infraestructura y a la salud pública. El umbral de precipitación (RT, por sus siglas en inglés) es el principal índice de alerta que se utiliza en China. Sin embargo, la cantidad de parámetros para el cálculo del RT es muy grande y la determinación de los valores de algunos de 
ellos es afectada por factores subjetivos. En este trabajo, el modelo progresivo MorrisSobol de dos capas (M-STPM, por sus siglas en inglés) se establece para identificar los parámetros sensibles para el cálculo del RT. Primero, el método de filtrado de Morris se aplica para el análisis cualitativo de la sensibilidad de los parámetros y los no sensibles se excluyen. Posteriormente se utiliza el método Sobol para cuantificar la sensibilidad. La sensibilidad de los parámetros para calcular el RT se determina a través de un estudio de caso en la villa de Duli, condado de Anyang, provincia de Henan. Los resultados indican que la media anual del punto máximo de precipitación 1-h es el parámetro más influyente. Se encontró que el cálculo de los parámetros en la relación del nivel de descarga de agua tiene una gran influencia en el RT, lo que muestra que el modelo propuesto puede proporcionar una referencia para determinar el valor de los parámetros $\mathrm{y}$, asimismo, dar un fundamento teórico para un futuro análisis del error en el cálculo del RT.

\section{INTRODUCTION}

Flash flood is a rapid-onset natural disaster with destructive power and serious damage (Hapuarachchi et al. 2011, Gascon et al. 2016, Ma et al. 2010, Halim and Phang 2017, Shamsudin et al. 2017). According to China Floods and Droughts Disasters Bulletin (http://www.mwr.gov.cn/zwzc/hygb/zgshzhgb), an annual average of about 838 deaths were caused by flash floods from 2012 to 2015. Such high losses and risks have underscored the need for flash flood warning and forecasting.

Flash flood is defined as a rapid and extreme flow of high water into a normally dry area, or a rapid water level rise in a stream or creek above a predetermined flood level, beginning within $6 \mathrm{~h}$ of the causative event (NWS 2016, Amiri et al. 2017). The Flash Flood Guidance (FFG) approach is widely employed in America and Europe (Villarini et al. 2010, Georgakakos 2006, Reed et al. 2007). FFG represents the depth of rain of a given duration, taken as uniform in space and time on a certain basin, necessary to cause minor flooding at the outlet of the considered basin (Norbiato et al. 2008, Qu et al. 2017).

The Rainfall Threshold (RT) is the main warning index of flash flood in China, and can be reasonably regarded as a prototype of the FFG. When the nowcasted or forecasted rainfall depth is greater than the RT, the flooding is considered likely to happen. As for the services of the Ministry of Water Resources, determination of RT has already been started at the village level. The mountainous areas account for almost two thirds of China's total land area (Yun et al. 2017, Tan et al. 2017). In addition, the small basis in mountainous areas are often ungauged, as they are short of monitoring facilities. Hence, the methods for calculating RT in China are mainly theoretical ones based on physical mechanism and hydrological theory, and empirical ones related to event correlation and geographical condition similarity. The theoretical methods include the Classical Hydrological Theory Method (CHTM), the Water Level-Discharge Inversion Method (WL-DIM), Rainfall Threshold Curve Method (RTCM), etc. The empirical approaches are composed of Statistical Induction Method (SIM), Analogy Method (AM), Interpolation Method (IM), etc. ( $\mathrm{Li}$ and Guo 2013).

In practice, it is difficult to calculate the accurate value of RT, due to a lack of data and affected by field measurements and subjective factors. Especially in small basins, when theoretical methods are applied, some parameters will be generalized or determined in a given range (Tariq et al. 2017). As a result, it is essential to analyze the sensitivity of parameters, namely, to determine the influence of each parameter on the RT, which can give a reference for the parameters value when the RT is calculated, and can lay the theoretical groundwork for further analyzing the RT error.

Sensitivity analysis is generally divided into local analysis and global analysis (Saltelli et al. 1999, Griensven et al. 2006). Local sensitivity analysis focuses on the effects of uncertain inputs around a point (or base case), whereas global sensitivity analysis concerns more about the influences of uncertain inputs over the whole input space (Song et al. 2015, Yasin et al. 2017). Global sensitivity analysis method falls into two categories: qualitative and quantitative types. Qualitative analysis methods include the Morris screening method, multiple regression method and LH-OAT method; quantitative analysis methods include Sobol method, Extend FAST method and GLUE method, etc. (Morris 1991, Sobol 1993, Francos et al. 2003, Beven and Binley 1992). The modified Morris screening method calculates the sensitivity of each parameter-based differential. This 
approach features minor computation and can handle multiple input parameters, but is devoid of analysis of interactions among parameters (Shin et al. 2013, Aziz and Hanfiah, 2017). The Sobol method based on variance decomposition has such advantages as working for non-linear models and analyzing the attribution of total output variance to individual parameters and their interactions, which is widely used in diverse fields. However, the Sobol algorithm has high computational costs.

Some studies have established a multilevel model, since it is capable of integrating the advantages of various methods (Wan et al. 2017, Ismail and Hanafiah 2017). Hence, the Morris-Sobol Two-layer Progressive Model (M-STPM) is established, with an aim to evaluate the influence of the parameters on RT and the effect of the interaction among the parameters on RT, aiming to improve the computational efficiency. In this model, the modified Morris screening method is used to analyze the qualitative sensitivity of each parameter, and goes a step further by applying the Sobol method to calculate the quantitative sensitivity. The RT in the case study of Duli Village of Anyang County in Henan Province is calculated, so as to identify the sensitivity and correlation of the parameters on RT, which helps determine the value of parameters in RT calculation.

This paper is structured as follows. First, the theoretical method of RT in China is introduced. Second, the Morris-Sobol Two-layer Progressive Model (MSTPM) is established. Third, the parameters in RT calculation and the experimental design of linear and stability analysis of parameters for RT response are determined in consideration of the case study of Duli Village. Finally, the results are presented, along with main research points summarized.

\section{THEORETICAL METHOD OF RAINFALL THRESHOLD (RT)}

Generally, precipitation forecast model and hydrological model is not widely available, due to the lack of rainfall data, hydrological data, basic surveying and mapping data and remote sensing data in small basins. Therefore, the theoretical method is often utilized to calculate RT. This paper takes the WL-DIM as an example to look into the sensitivity of parameters in RT calculation.

WL-DIM assumes that the frequency of rainfall is the same as that of flood (Li and Gua 2013). According to the bank-full water level $\left(Z_{b f}\right)$ at the control section of village and the water level-discharge curve $(Z-Q)$, the bank-full discharge $\left(Q_{b f}\right)$ is determined. Then RT is determined by $Q_{b f}$ and the curve of rainfall and flood peak $\left(P_{f}-Q_{f}\right)$. And the $P_{f}-Q_{f}$ curve is consistent with the rainfall-frequency curve $(P-f)$ and the curve of flood peak and frequency $(Q-f)$. The flow chart of WL-DIM is shown in Fig.1.

The calculation methods of design rainfall and design flood in small basins are usually chosen according to the local hydrological manual. The water level-discharge curve is often determined by Manning formula (Venutelli 2005). The formula is as follows:

$Q=\frac{1}{n} \cdot A \cdot R^{\frac{2}{3}} \cdot J^{\frac{1}{2}}$

Where $Q$ represents the discharge, $A$ is the area of the control section, $R$ is the hydraulic radius, $n$ is the roughness coefficient, which can be assumed based on characteristics of river bank (land use) and river bed (soil), and $J$ is the surface slope of flood, which is usually replaced by the slope of river bed in theoretical calculation.

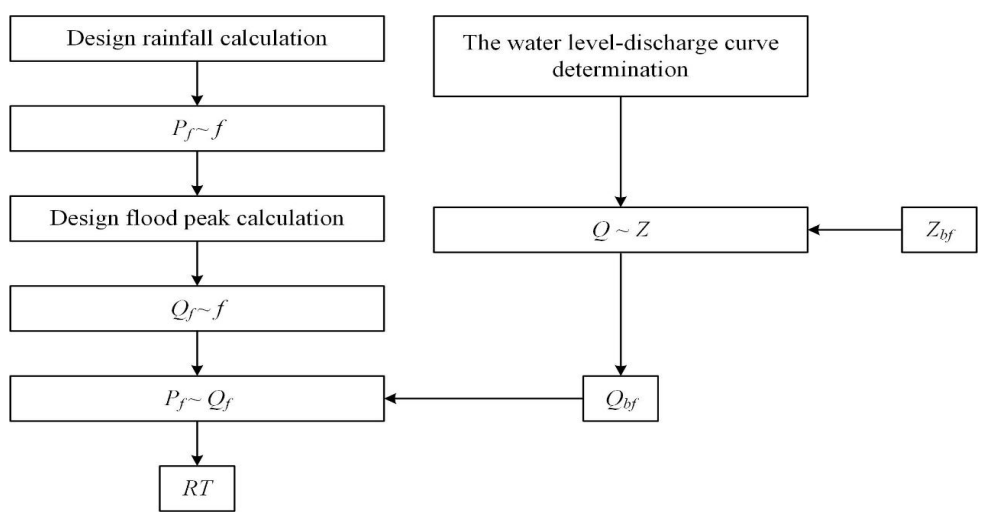

Fig. 1. Flow chart of the Water Level-Discharge Inversion Method (WL-DIM) 


\section{MORRIS-SOBOL TWO-LAYER PROGRESSIVE MODEL (M-STPM)}

The RT calculation consists of three parts: design rainfall calculation, design flood calculation and water level-discharge relation calculation, which involve many parameters. The sensitivity analysis of RT calculation parameters based on M-STPM is proposed, in order to improve computational efficiency in the sensitivity analysis of parameters. The basic principle is shown in Fig. 2.

\section{Qualitative analysis}

The Modified Morris Screening method serves to analyze qualitative sensitivity of parameters in RT calculation. As to changing the value of parameter $x_{i}$, the algorithm calculates the sensitivity discriminant factor $S$. The perturbation is determined by the fixed step length $C$ and the maximum amplitude $M$. The formula goes as follows:

$S=\sum_{i=0}^{Z-1} \frac{\frac{Y_{i+1}-Y_{i}}{Y_{0}}}{P_{i+1}-P_{i}} /(Z-1)$

Where $S$ represents the sensitivity discriminant factor, $Y_{0}$ is the RT value for the parameter initial value $x_{i}, Y_{i}$ is the RT value for the parameter value $x_{i}$ that corresponds to the change of the $i$ th perturbation, $P_{i}$ is the percentage change of the RT value for the parameter value $x_{i}$, which goes between its initial value and the value that corresponds to the change

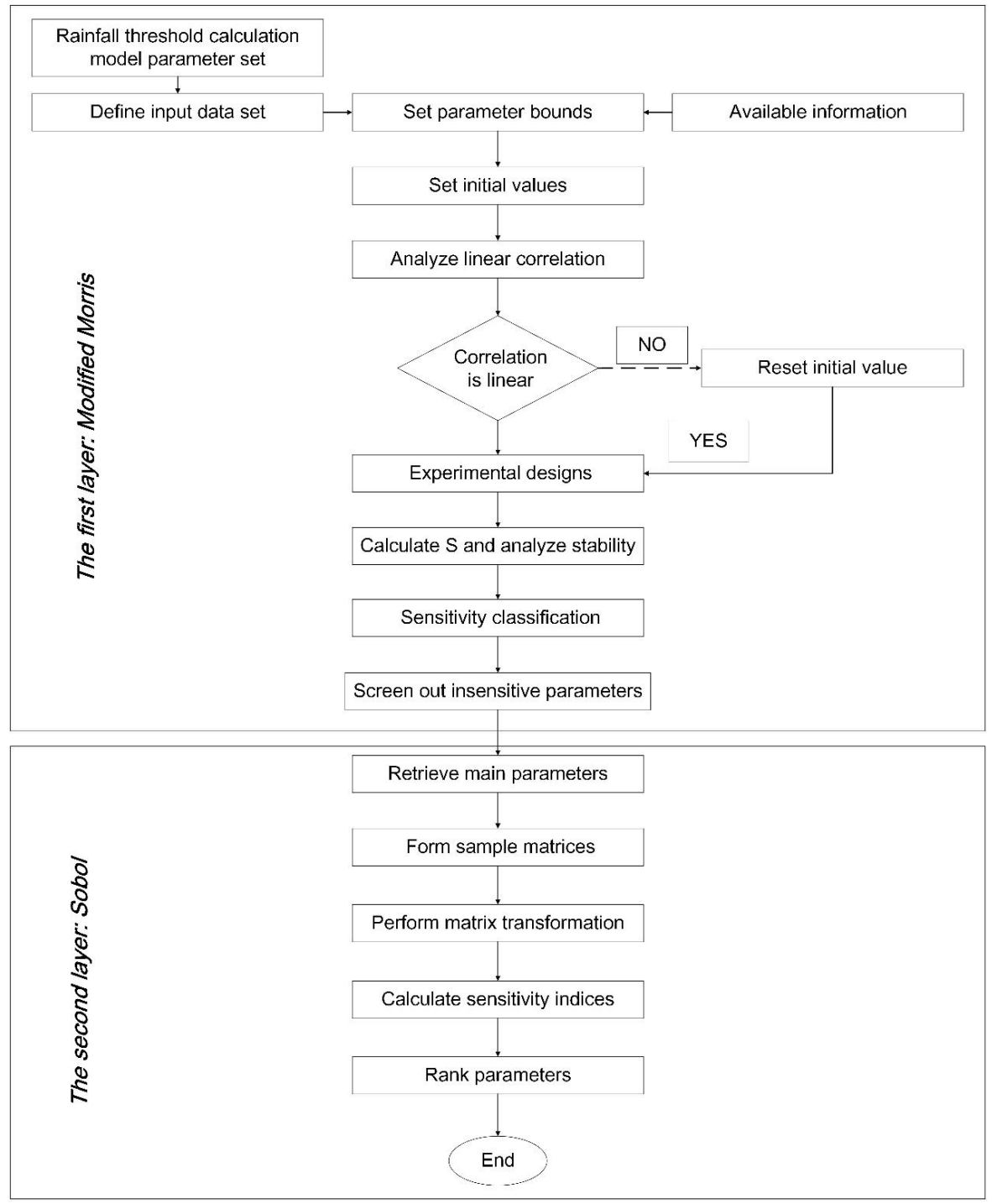

Fig. 2. The two-layer algorithm used in this study 
of the $i$ th perturbation, and $Z$ is the total number of disturbances, ie, experiment times, which is determined by the fixed step length $C$ and the maximum amplitude $M$.

Lenhart determined that if the response of target function to perturbation of a parameter is nonlinear, when the parameter sensitivity is calculated by a fixed percentage change, the result will depend on the choice of parameter initial value. That is to say, small initial values will result in small parameter sensitivity figures, and the reverse is also the case (Lenhart et al. 2002). Hence, linear correlation should be verified first when modified Morris screening method is used, that is, to analyze the linear correlation between parameters and the response of target function to perturbation of parameters. If the response is nonlinear, the corresponding parameter initial value should be preliminarily determined to mitigate the influence on analysis results.

Francos studied that $Z$ of Morris screening method can affect the sensitivity index. The results showed that when $Z$ are about 10 times, the stability of $S$ is better. Hence, scholars in many areas used the modified Morris screening method with a fixed step length of $5 \%$ and a maximum variation of $20 \%$ for sensitivity analysis (Francos et al. 2003, Song et al. 2014, Tan et al. 2015). However, $Z$ may depend on the specific case, either the model used or the investigated site or case, and several experiments might be necessary to achieve a favorable convergence of the ranking produced by the Morris method. Consequently, the stability of $S$ was studied, namely rating the fixed step length $C$ and the maximum amplitude $M$, by means of different experimental designs. Finally, the sensitivity classification is carried out until achieving the stability of $S$.

The parameter sensitivity classification is conducted, according to $S$ of each parameter. The sensitivity grade is shown in Table $\mathbf{I}$.

The insensitive parameters are screened out, according to the qualitative analysis results of each parameter, namely, the sensitivity classification. To make further progress, quantitative analysis for residual parameters will be carried out in this model.

TABLE I. SENSITIVITY CLASSIFICATION

\begin{tabular}{ll}
\hline Absolute value of $s$ & Sensitivity classification \\
\hline $0.00 \leq|s|<0.05$ & Insensitive parameter \\
$0.05 \leq|s|<0.2$ & Moderately sensitive parameter \\
$0.2 \leq|s|<1$ & Sensitive parameter \\
$|s| \geq 1$ & Highly sensitive parameter \\
\hline
\end{tabular}

\section{Quantitative analysis}

The variance-based Sobol method is used to quantitatively analyze the parameter sensitivity in the RT calculation (Sobol 1993). This method decomposes the output variance into contribution from individual parameters and their interactions.

Assuming that $Y=f(x)=f\left(x_{1}, x_{2}, \ldots x_{n}\right), Y$ is the RT, $x_{i}$ is the $i$ th parameter, according to variance decomposition theory. The equation has the following form:

$V(Y)=V\left(E\left(Y \mid x_{i}\right)+E\left(V\left(Y \mid x_{i}\right)\right.\right.$

Where $V(Y)$ represents the total variance of RT, $V\left(E\left(\left.Y\right|_{x_{i}}\right)\right.$ is the variance of conditional expectation of RT, and $E\left(V\left(\left.Y\right|_{x_{i}}\right)\right.$ is error term or residual term.

Calculation formulas of first-order sensitivity index and total sensitivity index can be obtained from Eq. (3) (Saltelli and Annoni 2010):

$S_{x_{i}}=\frac{V\left(E\left(Y \mid x_{i}\right)\right.}{V(Y)}$

$S_{x_{i}}^{T}=\frac{V(Y)-V\left(E\left(Y \mid x_{-i}\right)\right.}{V(Y)}$

Where $S_{x_{i}}$ represents the first-order sensitivity index, and $S_{x_{i}}^{T}$ is the total sensitivity index.

$S_{x_{i}}$ is the main effect of individual parameter on RT. The greater the first-order sensitivity index is, the greater the effect of the parameter has on RT will be. $S_{x_{i}}^{T}$ yields a parameter's total effect, which include all its interactions with other parameters. Under the condition where the total effect of the parameter is large, not only the individual parameter but its interactions with other parameters will have a powerful influence on the RT.

Sobol offered a Monte Carlo strategy to compute indices of any order, which is based on a Monte Carlo exploration of input space (Saltelli et al. 2005, Zhang 2014). From the range of $k$ parameters by Latin hypercube sampling $t$, we extract the following $A$ and $B$ two input matrixes:

$$
\begin{aligned}
A & =\left[\begin{array}{lllll}
x_{11} & \ldots & x_{1 i} & \ldots & x_{1 k} \\
x_{21} & \ldots & x_{2 i} & \ldots & x_{21} \\
\ldots & \ldots & \ldots & \ldots & \ldots \\
x_{n 1} & \ldots & x_{n i} & \ldots & x_{n k}
\end{array}\right], \\
B & =\left[\begin{array}{lllll}
x_{11}^{\prime} & \ldots & x_{1 i}^{\prime} & \ldots & x_{1 k}^{\prime} \\
x_{21}^{\prime} & \ldots & x_{2 i}^{\prime} & \ldots & x_{2 k}^{\prime} \\
\ldots & \ldots & \ldots & \ldots & \ldots \\
x_{n 1}^{\prime} & \ldots & x_{n i}^{\prime} & \ldots & x_{n k}^{\prime}
\end{array}\right]
\end{aligned}
$$


where each row of the matrix represents a combination of $k$ parameters, and each column represents the values of the randomly extracted parameters $x_{i}$. We obtain matrix $C_{i}$ by replacing the first column of the matrix $A$ in the Eq. (6) with the first column of the matrix $B$, keeping the remaining columns unchanged. We obtain matrix $C_{-i}$ by merely replacing the first column of the matrix $B$ in the Eq. (6) with the first column of the matrix $A$, as follows:

$$
\begin{aligned}
C_{i} & =\left[\begin{array}{ccccc}
x_{11} & \ldots & x_{1 i}^{\prime} & \ldots & x_{1 k} \\
x_{21} & \ldots & x_{2 i}^{\prime} & \ldots & x_{21} \\
\ldots & \ldots & \ldots & \ldots & \ldots \\
x_{n 1} & \ldots & x_{n i}^{\prime} & \ldots & x_{n k}
\end{array}\right], \\
C_{-i} & =\left[\begin{array}{ccccc}
x_{11}^{\prime} & \ldots & x_{1 i} & \ldots & x_{1 k}^{\prime} \\
x_{21}^{\prime} & \ldots & x_{2 i} & \ldots & x_{2 k}^{\prime} \\
\ldots & \ldots & \ldots & \ldots & \ldots \\
x_{n 1}^{\prime} & \ldots & x_{n i} & \ldots & x_{n k}^{\prime}
\end{array}\right]
\end{aligned}
$$

The RT is calculated with the parameters in matrix $A, B, C_{i}$, and $C_{-i}$. The corresponding variance and parameter sensitivity indexes are respectively calculated according to Eq. (8) to Eq. (13) as follows:

$$
\begin{aligned}
\hat{f}_{0}^{2}= & \frac{1}{n} \sum_{r=1}^{n} f\left(x_{r 1}, x_{r 2}, \ldots, x_{r k}\right) f\left(x_{r 1}^{\prime}, x_{r 2}^{\prime}, \ldots, x_{r k}^{\prime}\right) \\
\hat{V}(\mathrm{y}) & =\frac{1}{n} \sum_{r=1}^{n} f^{2}\left(x_{r 1}, x_{r 2}, \ldots, x_{r k}\right)-\hat{f}_{0}^{2} \\
\hat{U}_{i}= & \frac{1}{n} \sum_{r=1}^{n} f\left(x_{r 1}, x_{r 2}, \ldots, x_{r k}\right) \\
& f\left(x_{r 1}^{\prime}, \ldots, x_{r(i-1)}^{\prime}, x_{r i}, x_{r(i+1)}^{\prime}, \ldots, x_{r k}^{\prime}\right) \\
\hat{U}_{-i} & =\frac{1}{n} \sum_{r=1}^{n} f\left(x_{r 1}, x_{r 2}, \ldots, x_{r k}\right) \\
& f\left(x_{r i}, \ldots, x_{r}(i-1), x_{r i}^{\prime}, x_{r(i+1)}, \ldots, x_{r k}\right) \\
\hat{S}_{x_{i}}= & \frac{\hat{U}_{i}-\hat{f}_{0}^{2}}{V(y)} \\
\hat{S}_{x_{i}}^{T}= & 1-\frac{\hat{U}_{-i}-\hat{f}_{0}^{2}}{\hat{V}(y)}
\end{aligned}
$$

$\hat{f}_{0}^{2}$ is the mean of matrix $A$ and $B ; \hat{V}(y)$ the approximate number of RT; $\hat{U}_{i}$ the mean of matrix $A$ and $C_{i}$; $\hat{U}_{-i}$ the mean of matrix $A$ and $C_{i} ; S_{x_{i}}$ the first-order sensitivity index; $S_{x_{i}}^{T}$ the aggregate sensitivity index.

\section{DATA AND MATERIALS}

The case study is conducted upon Duli village. Duli village of Anyang county, covering an area of $69.11 \mathrm{~km}^{2}$, is located in north of Henan province (latitude between $35^{\circ} 35^{\prime}$ and $36^{\circ} 21^{\prime} \mathrm{N}$, longitude between $113^{\circ} 35^{\prime}$ and $114^{\circ} 45^{\prime}$ E), as shown in Fig. 2 . The landscape of the village is high in the west and low in the east, featured by hills, mounds, plains, and depression. The small basin enjoys a typical temperate monsoon climate, featured by uneven rainfall in both temporal and spatial terms. The average annual rainfall is about $510 \mathrm{~mm}$. The flood level of control section in this small basin is 220.15 $\mathrm{m}$. This paper takes 1-h RT calculation process as an example.

\section{Parameter determination}

The WL-DIM is used to calculate RT. According to Fig.1, WL-DLM includes design rainfall calculation, design flood and the water level-discharge curve determination. Design rainfall calculation is based on the hydrological manual of Henan, calculated as follows:

$H_{t, f}=\bar{H} \cdot\left[1+C_{v} \Phi\left(f, C_{s}\right)\right]$

Where $\mathrm{H}$ is $\mathrm{t}-\mathrm{h}$ design rainfall with design frequency $\mathrm{f}, \mathrm{H}$ the mean of $\mathrm{t}-\mathrm{h}$ annual maximum rainfall, $C_{v}$ the coefficient of variation, $\Phi$ a frequency factor, $\mathrm{f}$ the frequency, and $C_{s}$ coefficient of skewness. H and $C_{v}$ are determined based on the geographical location, hydrological division of village and contour map in the hydrological manual of Henan. For the $f$ and $C_{S}$, $\Phi$ can be obtained from the table of $\Phi$. In this paper, $C_{s} / C_{v}=3.5$.

Taking 1-h RT calculation as an example, the design rainfall parameters include the mean of 1-h annual maximum rainfall $\bar{H}_{1}$ and coefficient of variation $C_{v}$.

As the surface area of the small basin is less than $200 \mathrm{~km}^{2}$; the rational formula is commonly applicable to flood in the basin. According to the hydrological manual of Henan, the rational formula is as follows:

$Q_{m}=0.278 \psi \frac{\boldsymbol{S}_{p}}{\tau^{n}} F$ 
Where $Q_{m}$ is the design peak flow with design frequency $f, \psi$ the runoff coefficient, $S_{p}$ the design rainfall depth in one hour, $\tau$ the time of concentration, and $n_{i}(i=1,2,3)$ a coefficient called storm index. $F$ is the basin area, and 0.278 a coefficient for transferring the dimension.

$S_{p}$ is calculated by

$S_{p}=H_{24, f} \cdot 24^{\wedge}(n 2-1)$

$\tau$ is calculated by

$\tau=0.278 \frac{L}{m J^{1 / 3} Q^{1 / 4}}$

Where $L$ is the basin length, $m$ a coefficient of routing, related to the hydraulic properties of the flow and basin's physical characteristics, and $J$ the river average slope.

When the rainfall-runoff duration $t_{c}$ is greater than $\tau, \psi$ is calculated by equation; when the $t_{c}$ is less than $\tau, \psi$ is calculated by equation

$\psi=1-\frac{\mu}{S} \tau^{n}$

Where $\mu$ is the infiltration loss coefficient.

$\psi=n_{i} \cdot\left(t_{c} / \tau\right)^{\wedge}\left(1-n_{i}\right)$

Taking the rational formula as an example, the design flood parameters include infiltration loss coefficient $\mu$, basin area $A$, basin length $L$, the river average slope $J$, mean of 24-h annual maximum point rainfall $\bar{H}_{24}$ and storm index $n_{i}$.

Manning formula was used to determine water level-discharge relation, which include roughness $n$ and water surface slope $i$.

For a given small basin, its geometric characteristic parameters, including basin area $A$, basin length $L$ and river average slope $J$, are unchanged in the short term. Thus they were not selected as parameters in sensitivity analysis.

Following the hydrological manual of Henan, we consider the natural geography, topography, hydrology, meteorology and hydrological regionalization of Duli. We calculate the range of parameters and initial values, as presented in Table II.

\section{Linear and stability analysis of parameters for RT response}

In the established model, the modified Morris screening method is applied to analyze the sensitivity of each parameter in Table II in the first layer. It was stated previously that the linear correlations
TABLE II. PARAMETERS RANGES AND VALUES

\begin{tabular}{lcc}
\hline Parameters & Range & $\begin{array}{l}\text { Initial } \\
\text { value }\end{array}$ \\
\hline Mean of 24 -h annual maximum point & & \\
rainfall $\bar{H}_{24}$ & $100 \sim 110$ & 101 \\
Mean of 1-h annual maximum point & & \\
rainfall $\bar{H}_{1}$ & $40 \sim 45$ & 43 \\
Variation coefficient $C_{v}$ & $0.6 \sim 0.7$ & 0.6 \\
Storm index $n_{1}$ & $0.55 \sim 0.6$ & 0.55 \\
Storm index $n_{2}$ & $0.7 \sim 0.75$ & 0.7 \\
Storm index $n_{3}$ & $0.75 \sim 0.8$ & 0.75 \\
Infiltration loss coefficient $\mu$ & $5 \sim 8$ & 6.5 \\
Roughness $n$ & $0.025 \sim 0.06$ & 0.038 \\
Water surface slope $i$ & $0.005 \sim 0.009$ & 0.005
\end{tabular}

between parameters and the response of the RT to changes of parameters need to be analyzed, and multiple experiments might be needed to achieve the convergence of the ranking produced by the modified Morris screening method. Therefore, each parameter changes according to a scheme with 5\% for the fixed step size $C$ and $20 \%$ for the maximum amplitude $M$. We then calculate the values of corresponding RT and analyze the linear correlations between parameters and the response of RT to changes of parameters. Experimental schemes shown in Table III, were designed to study the stability of the sensitivity discrimination factor $S$ of each parameter. In other words, first rate $C$ and $M$, then determine the total number of disturbances $Z$ corresponding to $S$ in steady state. The sensitivity of the parameters is classified by a stable $S$ and the parameters above moderately sensitive parameter are filtrated. The Sobol method is used to conduct quantitative analysis of the selected parameters, and finally calculating the sensitivity of parameters in RT.

TABLE III. MODIFIED MORRIS SCREENING METHOD EXPERIMENTAL DESIGN

\begin{tabular}{lccccc}
\hline \multicolumn{6}{c}{ The first group: fix step size $C(5 \%)$} \\
\hline Item & 1 & 2 & 3 & 4 & 5 \\
\hline The maximum amplitude $M$ & $10 \%$ & $15 \%$ & $20 \%$ & $25 \%$ & $30 \%$ \\
\hline \multicolumn{7}{c}{ The second group: fix the maximum amplitude } & $M(20 \%)$ \\
\hline Item & 1 & 2 & 3 & 4 & 5 \\
\hline Step size $C$ & $0.5 \%$ & $1 \%$ & $2 \%$ & $4 \%$ & $5 \%$ \\
Experiment times $Z$ (times) & 81 & 41 & 21 & 11 & 9 \\
\hline
\end{tabular}




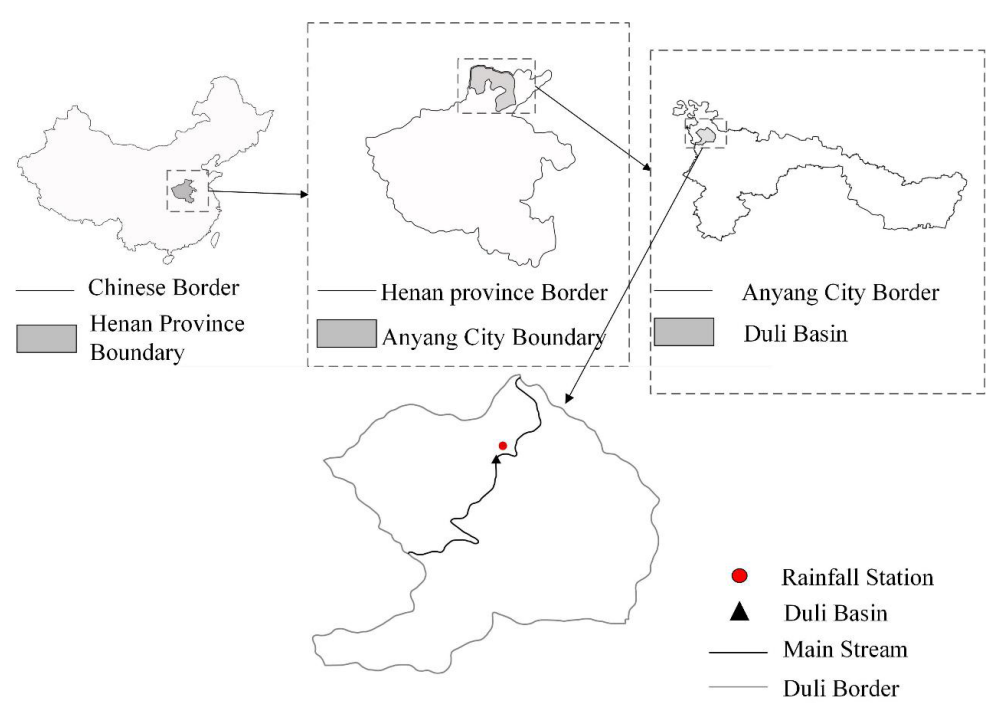

Fig. 3. The location of Duli basin

\section{RESULTS AND DISCUSSION}

\section{Qualitative analysis results}

Analyzing the linear correlation between parameters and the response of RT to changes of parameters, we gain results as shown in Fig. 4-12.

The response of RT to the parameters, including the mean of 1-h annual maximum point rainfall $\bar{H}_{1}$, storm index $n_{2}$, infiltration loss coefficient $\mu$ and water surface slope $i$, is linearly positive to the corresponding parameters, while the mean of 24-h annual maximum point rainfall $\bar{H}_{24}$ and roughness $n$ are negative to the corresponding parameters. And there is no change in the response of RT to the parameters which include storm index $n_{1}$ and $n_{3}$. The RT

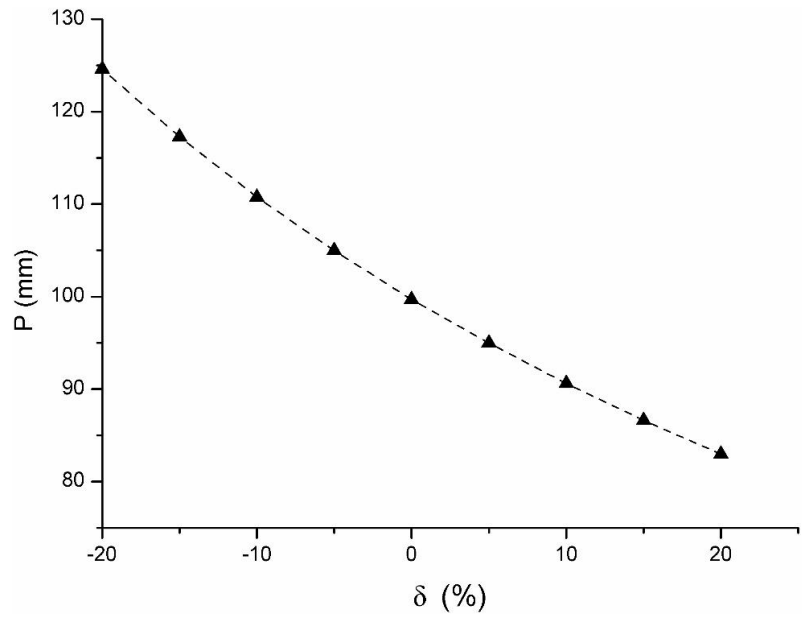

Fig. 4. Response of RT to $\bar{H}_{24}$

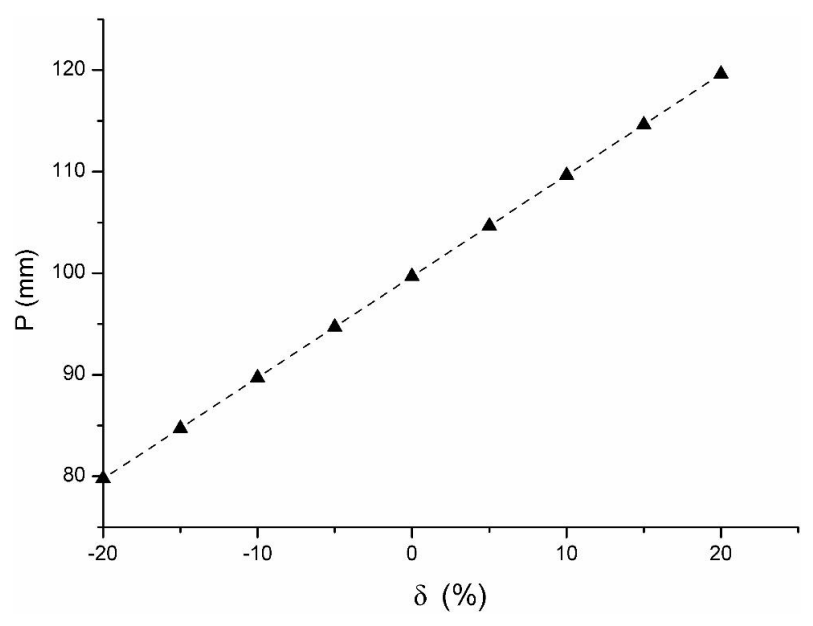

Fig. 5. Response of RT to $\bar{H}_{1}$

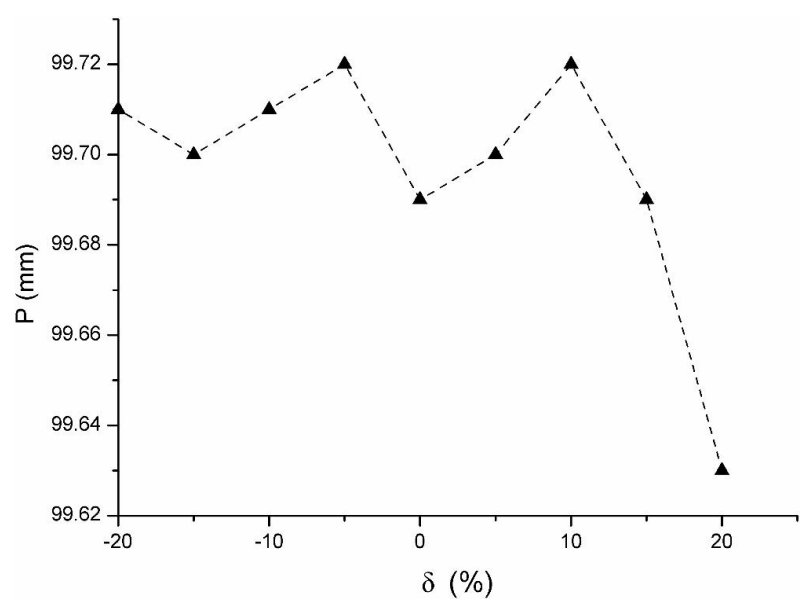

Fig. 6. Response of RT to $C_{v}$ 


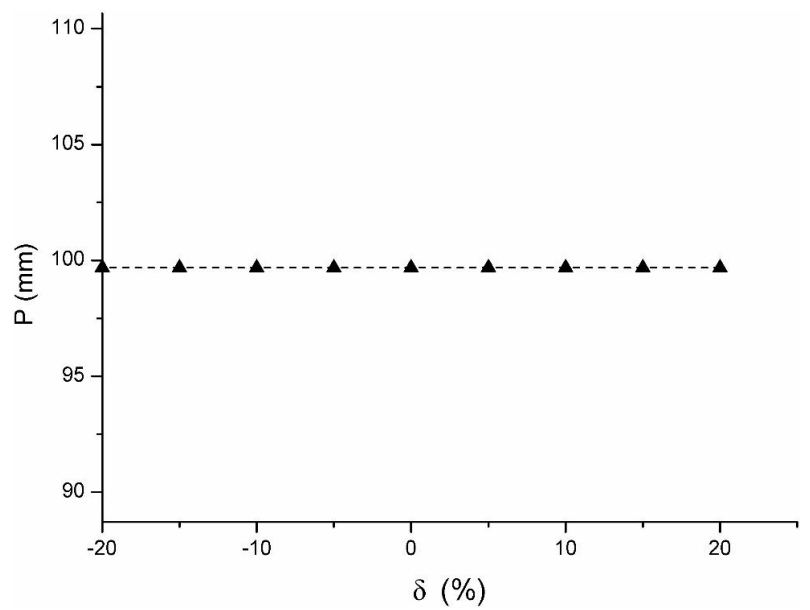

Fig. 7. Response of RT to $n_{1}$

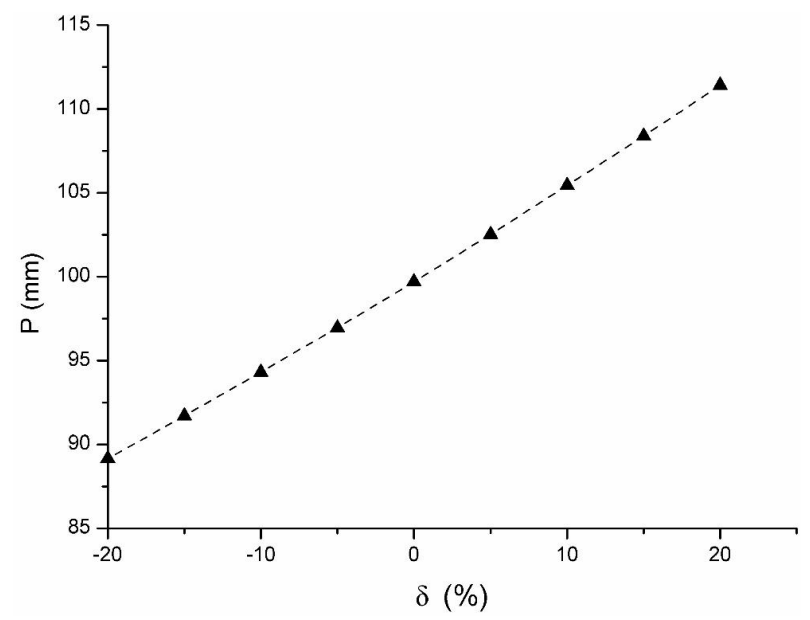

Fig. 8. Response of RT to $n_{2}$

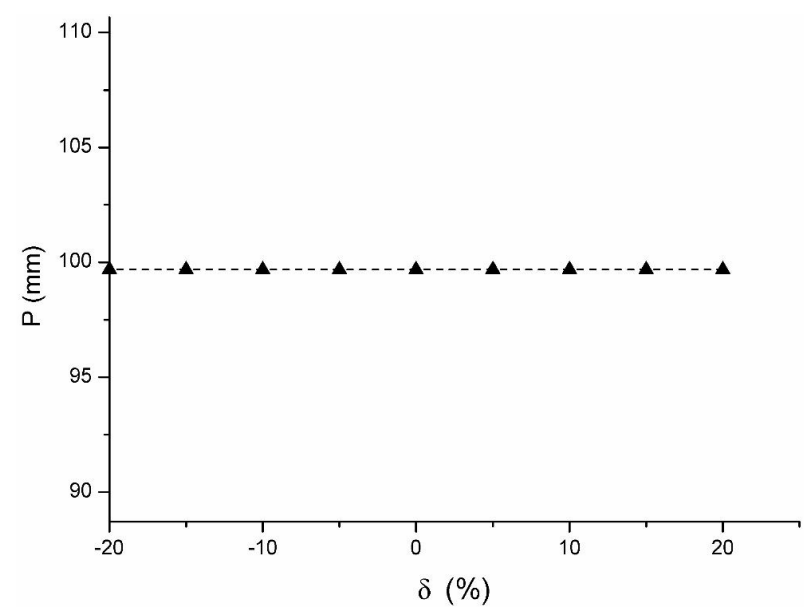

Fig. 9. Response of RT to $n_{3}$

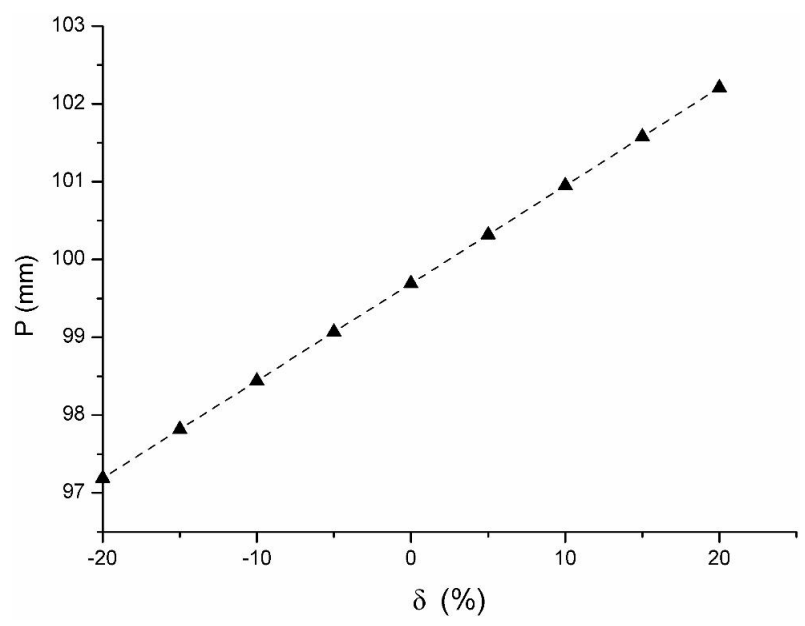

Fig. 10. Response of RT to $\mu$

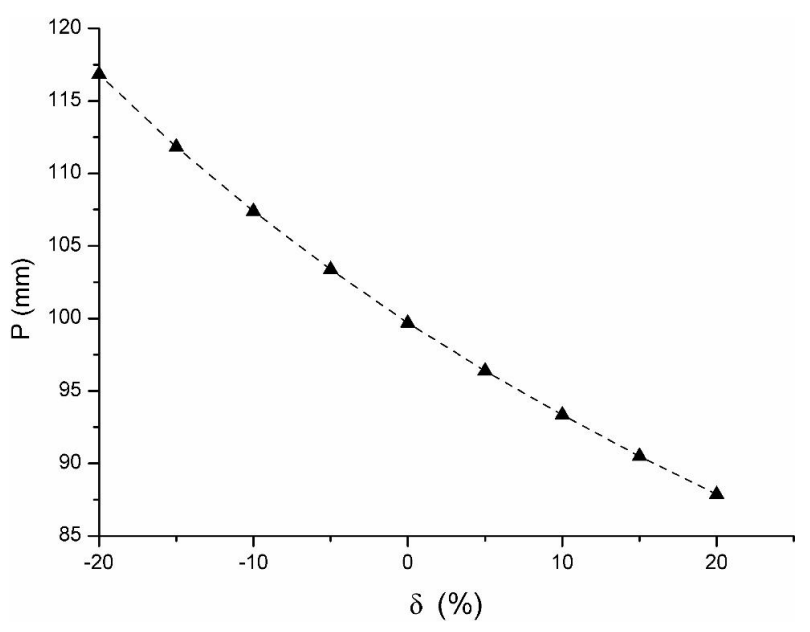

Fig. 11. Response of RT to $n$

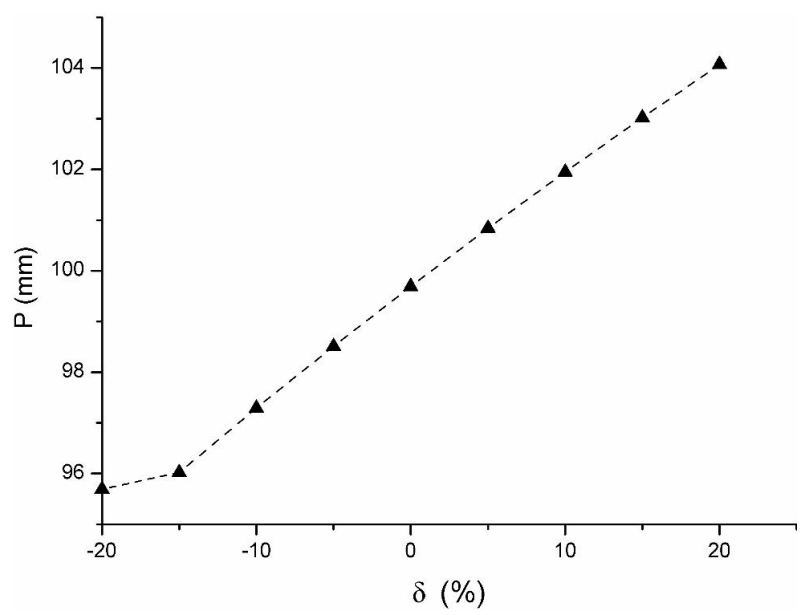

Fig. 12. Response of RT to $i$ 
is nonlinear for the variation of variation coefficient $C_{v}$. Therefore, referring to the "variation coefficient contour map" and the position of the village in the map sets of design rainstorm, the initial value of $C_{v}$ is 0.62 based on the proportion linear difference.

According to the experimental designs listed in Table III, results of the first group stay unchanged: parameters change in fixed step $C(5 \%)$, and the varied maximum amplitude $M$ still reflects the sensitivity discriminant factor $S . M$ is fixed but $C$ is changed in the second group. Fig. 13 to 21 show how $S$ of each parameter vary as the times of experiments performed $(Z)$ increases.

The $S$ of $\bar{H}_{1}, C_{v}, n_{1}$ and $n_{3}$ are basically unchanged as $Z$ increases. Step size $C$ and maximum amplitude $M$ can be $5 \%$ and $20 \%$ respectively. The $S$ of the other 5 parameters when $Z$ increases, gradually reaching

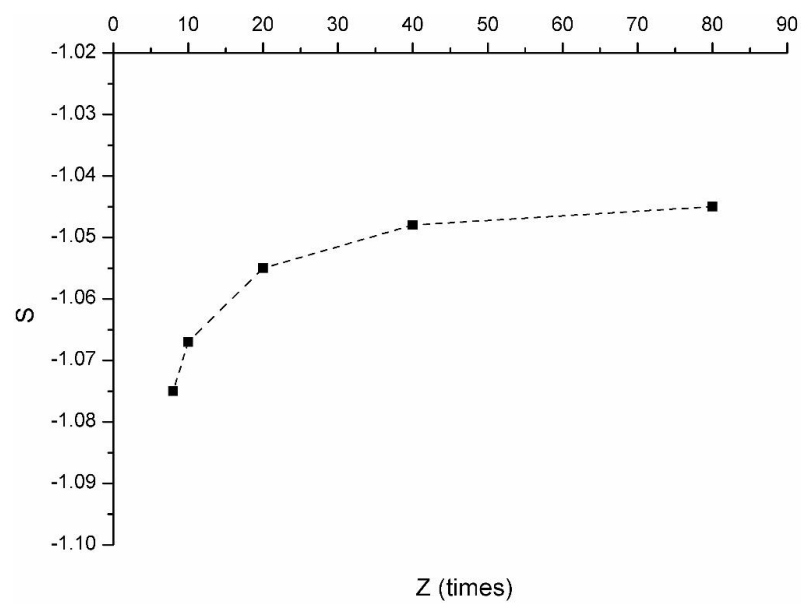

Fig. 13. Changes of $S$ for $\bar{H}_{24}$ as experiments increase

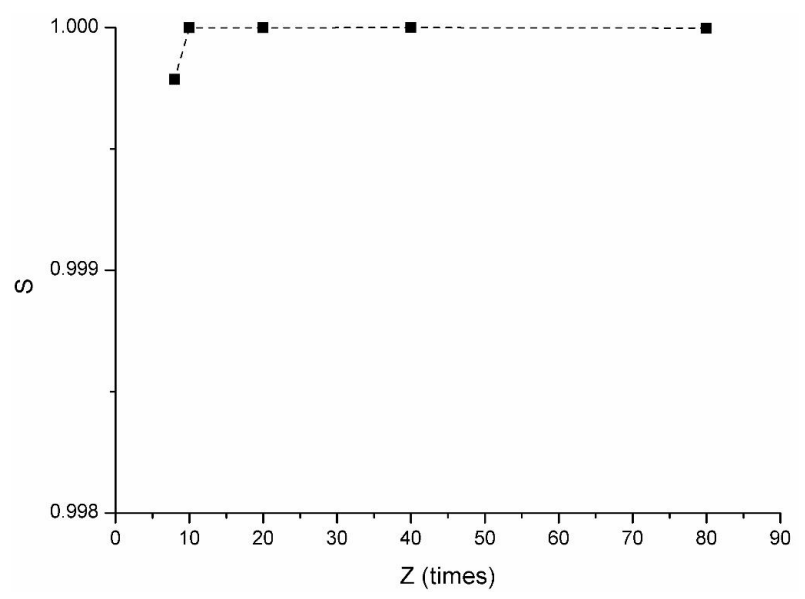

Fig. 14. Changes of $S$ for $\bar{H}_{1}$ as experiments increase

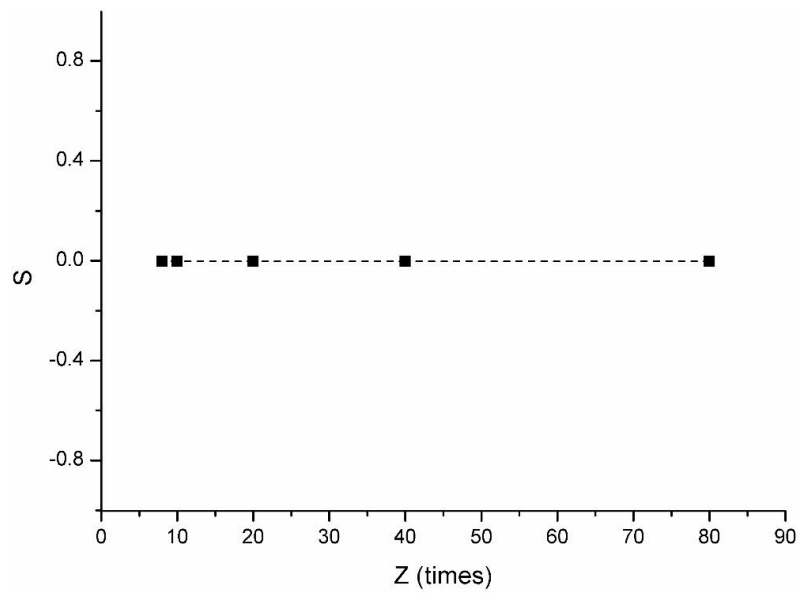

Fig. 15. Changes of $S$ for $C_{v}$ as experiments increase

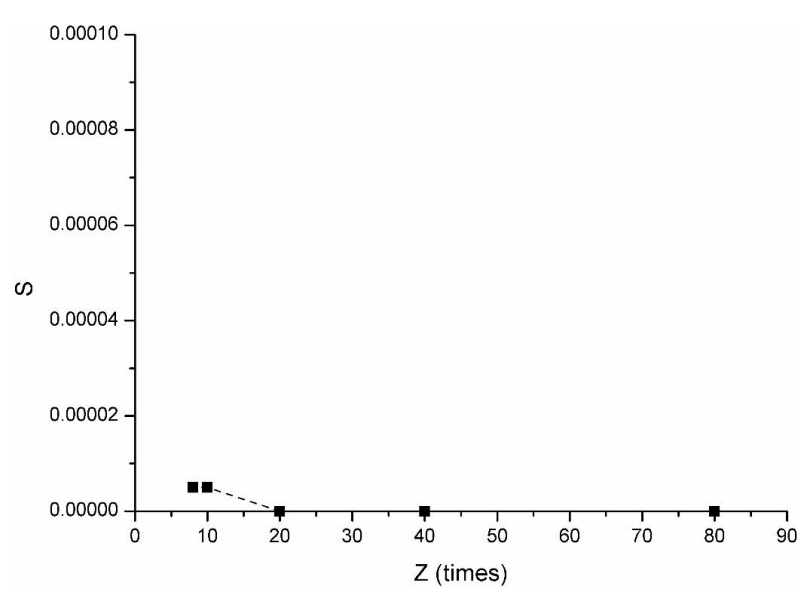

Fig. 16. Changes of $S$ for $n_{1}$ as experiments increase

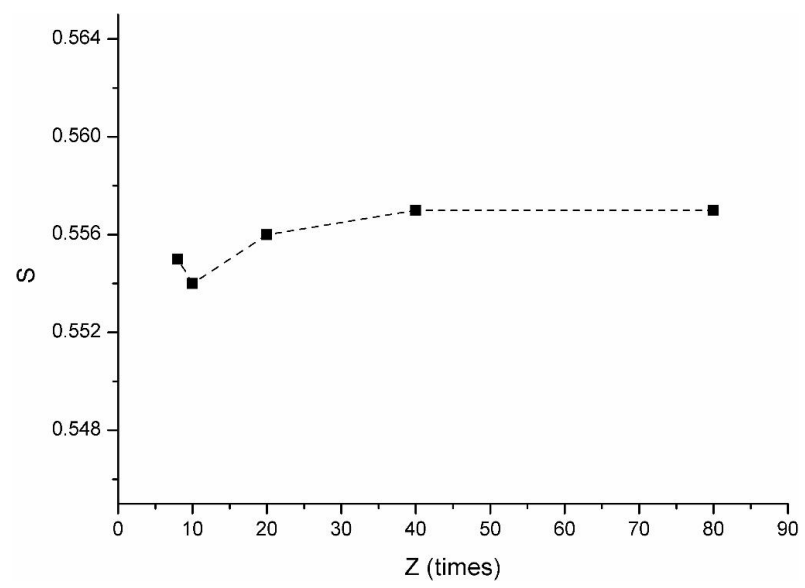

Fig. 17. Changes of $S$ for $n_{2}$ as experiments increase 


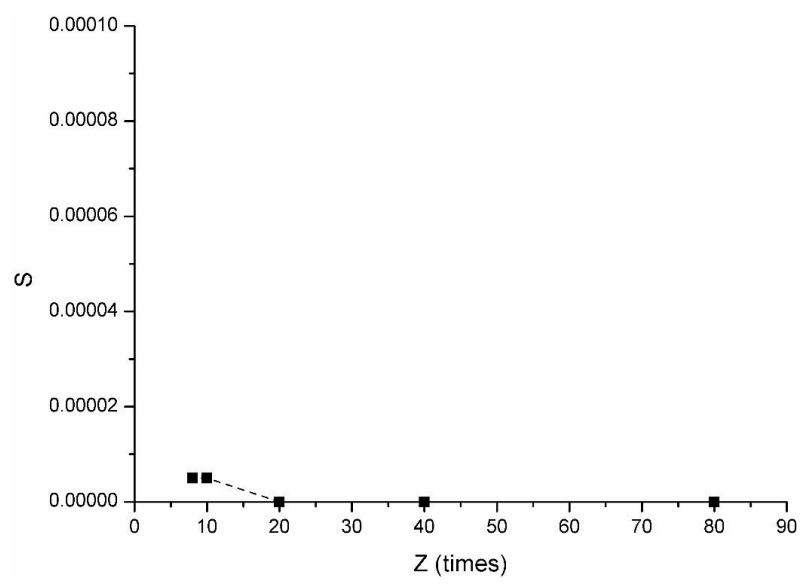

Fig. 18. Changes of $S$ for $n_{3}$ as experiments increase

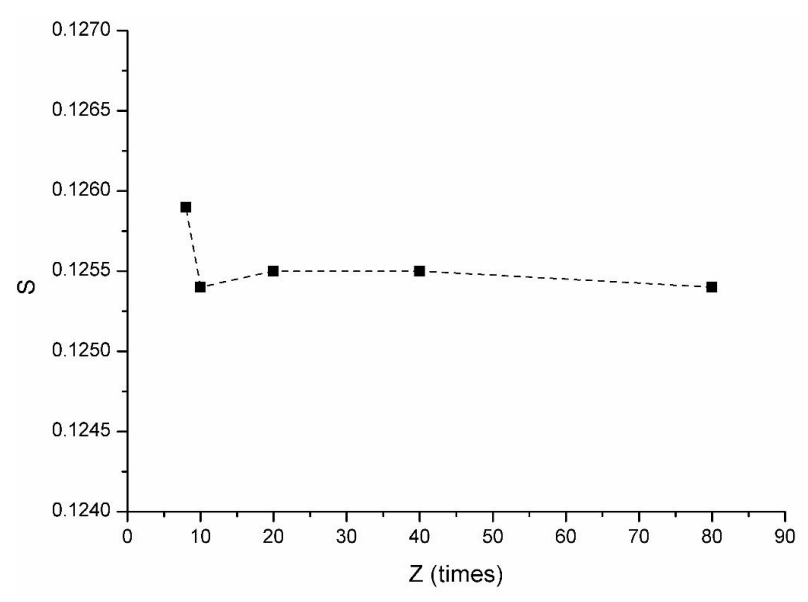

Fig. 19. Changes of $S$ for $\mu$ as experiments increase

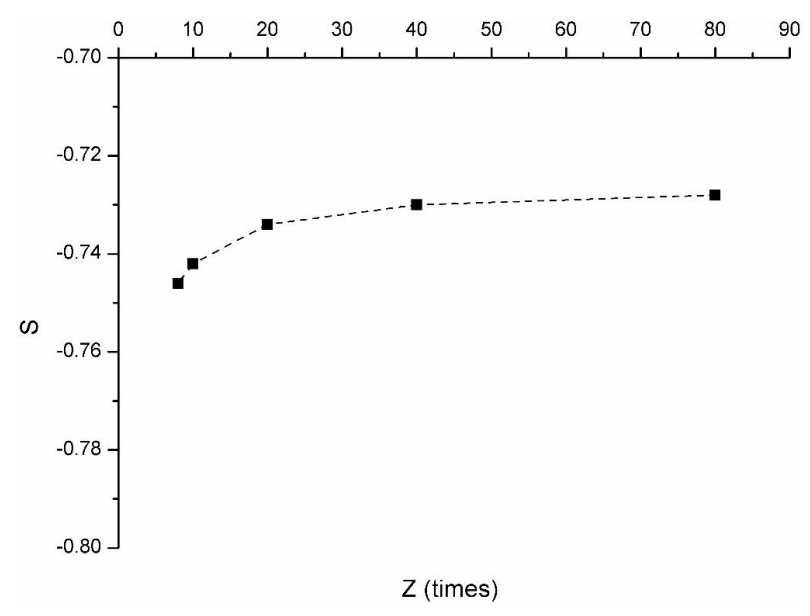

Fig. 20. Changes of $S$ for $n$ as experiments increase

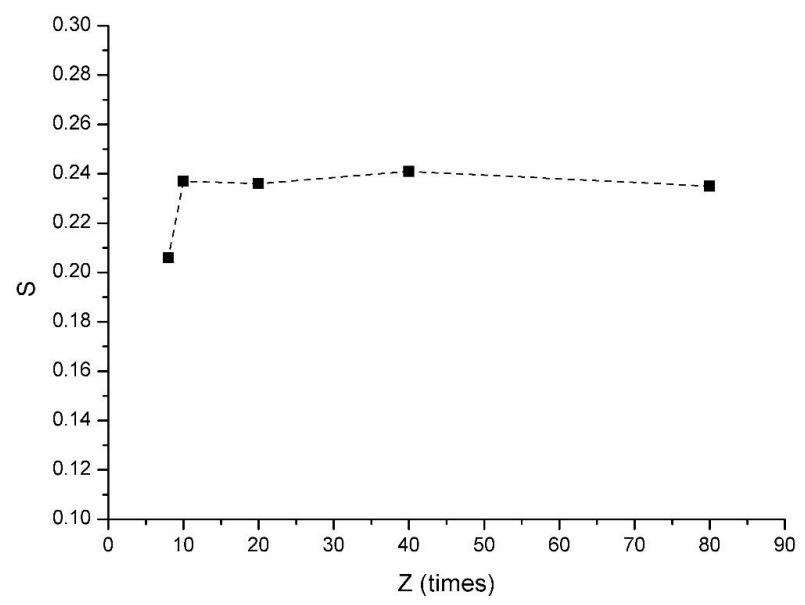

Fig. 21. Changes of $S$ for $i$ as experiments increase

stability when $Z$ is greater than 10 . Hence for the five parameters, unreliable are the results of experiments with $C$ fixed to $5 \%$ and $M$ to $20 \%$. $Z$ required for the sensitivity discriminant factor $S$ to achieve stability is shown in Table IV.

TABLE IV. EXPERIMENT TIMES $Z$ OF EACH PARAMETER THAT $S$ REQUIRES REACHING STABILITY

\begin{tabular}{lccccc}
\hline Parameters & $\bar{H}_{24}$ & $n_{2}$ & $\mu$ & $n$ & $n$ \\
\hline The experiment times $Z$ (times) & 80 & 40 & 80 & 40 & 80 \\
\hline
\end{tabular}

Table IV shows that also unreliable is the $S$ of 5 parameters among 9 qualitative analysis parameters, which are calculated by setting $Z$ at 10 . In other words, $Z$ of $S$ can only reach stability when more than half of the parameters in RT calculation are greater than 10 times.

Not only in the sensitivity analysis of parameters in RT calculation, but also in other research fields, the stability analysis of the sensitivity discriminant factor $S$ should also be carried out when the modified Morris screening method is applied, rating the step size $C$ and the maximum amplitude $M$ to obtain more accurate parameter sensitivity classification.

According to Fig 12 to 20, the sensitivity determination factors $S$ for each parameter are listed in Table V.

It can be seen that there are 3 insensitive parameters in RT calculation of flash flood, namely, the variation coefficient $C_{v}$, storm index $n_{1}$ and $n_{3} ; 1$ moderately sensitive parameter, namely, infiltration loss coefficient $\mu$; 4 sensitive parameters, namely, 
TABLE V. SENSITIVITY ANALYSIS RESULTS OF MODIFIED MORRIS SCREENING METHOD

\begin{tabular}{lc}
\hline Parameters & $S$ \\
\hline Mean of 24-h annual maximum point rainfall $\bar{H}_{24}$ & -1.045 \\
Mean of 1-h annual maximum point rainfall $\bar{H}_{1}$ & 0.999 \\
Variation coefficient $C_{v}$ & -0.002 \\
Storm index $n_{1}$ & 0 \\
Storm index $n_{2}$ & 0.557 \\
Storm index $n_{3}$ & 0 \\
Infiltration loss coefficient $\mu$ & 0.125 \\
Roughness $n$ & -0.728 \\
Water surface slope $i$ & 0.235 \\
\hline
\end{tabular}

the mean of 1-h annual maximum point rainfall $\bar{H}_{1}$, storm index $n_{2}$, roughness $n$ and water surface slope $i$.; 1 highly sensitive parameter, namely, the mean of 24-h annual maximum point rainfall $\bar{H}_{24}$.

Based on the qualitative analysis of the first layer of the model, we select 6 parameters above moderate sensitivity as the parameters of quantitative analysis, namely, $\mu, \bar{H}_{1}, n_{2}, n, i$ and $\bar{H}_{24}$. The aim is to screen out insensitive parameters, reduce the input parameter of quantitative analysis, improve efficiency of analysis and ensure that the parameters in the research system are fully analyzed and calculated.

\section{Quantitative analysis results}

The second layer of sensitivity analysis is carried out based on the selected 6 sensitive quantitative analysis parameters and their range. Latin hypercube sampling is conducted, obtaining 2000 samples. The first-order sensitivity indexes and the total sensitivity indexes of 6 parameters are calculated according to the Sobol method, as listed in Table 6. Column 2 shows the results of the first-order sensitivity index $S_{x_{i}}^{T}$, column 3 the results of the total sensitivity index $S_{x_{i}}^{T}$ and corresponding ranks are shown in column 4 .

Column 2 of Table VI shows that $\bar{H}_{1}$ is the most influential single parameter to RT, followed by $n, i$, $n_{2}, \mu$ and $\bar{H}_{24}$. Parameter $\bar{H}_{1}$ has nearly 2 times more impact on RT than $n(\operatorname{rank} 2)$ and 12 times than $i . \bar{H}_{1}$ is the critical parameter in design storm calculation, which has a direct influence on the value of RT. The value of $S_{x_{i}}$ for $n_{2}$ and $\mu$ are only -0.0038 and -0.0087 respectively. Because of their small $S_{x_{i}}$ values, we think that they have less effect upon RT.

Column 3 shows that $\bar{H}_{1}$ is the most important parameter for the total effect, followed by $n, i, n_{2}, \mu$ and $\bar{H}_{24}$. The ranks of each parameter for the firstorder sensitivity index $S_{x_{i}}$ and the total sensitivity index $S_{x_{i}}^{T}$ are the same.
TABLE VI. SENSITIVITY ANALYSIS RESULTS OF SOBOL METHOD

\begin{tabular}{lrcc}
\hline Parameters & $S_{x i}$ & $S_{x i}^{T}$ & Rank \\
\hline Mean of 24-h annual & & & \\
maximum point rainfall $\bar{H}_{24}$ & -0.1776 & -0.1985 & 6 \\
Mean of 1-h annual & & & \\
maximum point rainfall $\bar{H}_{1}$ & 0.7269 & 0.746 & 1 \\
Storm index $n_{2}$ & -0.0038 & -0.0047 & 4 \\
Infiltration loss coefficient $\mu$ & -0.0087 & -0.0078 & 5 \\
Roughness $n$ & 0.3865 & 0.4135 & 2 \\
Water surface slope $i$ & 0.0601 & 0.0705 & 3 \\
\hline
\end{tabular}

Theoretically the value of total sensitivity index $S_{x_{i}}^{T}$ is equal to or greater than the first-order sensitivity index $S_{x_{i}}$. Yet for some parameters, the result is reverse. Because of numerical integration, some values of $S_{x_{i}}^{T}$ and $S_{x_{i}}$ may be negative (Xu et al. 2012).

The major and aggregate impact of $\bar{H}_{1}$ upon RT is much greater than that of the rest of the parameters. Therefore, when the design storm or the observed rainfall is applied to calculate the RT, the precision of short-term rainfall should be paid attention to.

Roughness $n$ also has greater influence on the RT. However, in practical engineering, its value is usually determined according to river characteristics with reference to "the table of natural river roughness". Obviously, the function of the subjective factors exists in the RT calculation (Kylili et al. 2018, Gao et al. 2017, Shen et al. 2017). Therefore, in order to improve the accuracy of RT, we should focus on the analysis of $n$ when determining the value of parameters in the RT calculation of flash flood. When the measured hydrological data is sufficient, the measured hydrological data should be applied to calculation. When the measured hydrological data is lacking, an optimal value should be selected by considering the river channel characteristics, vegetation growth, bed roughness and other factors.

As mentioned above, the calculation of RT usually includes three parts: design rainfall calculation, design flood calculation and water level-discharge curve calculation. However, we discover that the water level-discharge relation parameters occupies a dominant position. These parameters include roughness $n$ (rank 2) and water surface slope $i$ (rank 3 ). Therefore, we should strengthen the study of water level-discharge relation parameters and improve the quality of early warning and forecasting of flash flood (Rusanow et al. 2016, Pina-Garcia et al. 2016, Kim et al. 2018).

When determining the valve of parameters in RT calculation of flash flood, we should strengthen the 
study of the larger sensitivity parameters to improve the accuracy of RT and enhance the accuracy of flash flood warning (Wang et al. 2017) according to the rank of sensitivity parameters.

\section{CONCLUSIONS}

In this paper, we have established a Morris-Sobol Two-layer Progressive Model (M-STPM). The sensitivity of parameters in RT calculation is analyzed with this model. The modified Morris Screening Method in the first layer is applied to the qualitative analysis of the parameters in the RT calculation. We also analyze the linear correlations between parameters and the response of the RT to changes of parameters and the times of experiments $\mathrm{Z}$ that the sensitivity discrimination factor $S$ of each parameter requires to achieve stability.

The parameters screened out in this layer helps to improve computational efficiency. The Sobol method applied to the second layer provides quantitative measures of sensitivity. The sensitive parameters need to be optimized while the less sensitive parameters are fixed to a certain value.

Some useful experimental results are obtained. Namely, $Z$ of the sensitivity discriminant factors $S$ needs to be greater than 10 for more than half of the parameters in RT calculation to reach stability. Thus, the stability analysis of the $S$ should also be carried out to obtain a more accurate parameter sensitivity classification when extended to other study fields applying the modified Morris Screening Method.

Besides, the mean of 1-h annual maximum rainfall $\bar{H}_{1}$ has the most significant first-order and total effects on the RT. Therefore, we should pay attention to the precision of short-term rainfall when the design storm or the observed rainfall is used to calculate the RT. The influence of the roughness $n$ on the RT is also great, the value of which should be studied and analyzed. On the one hand, when the measured hydrologic data are available, the value of $n$ can be calculated through them. On the other hand, when the measured hydrologic data are missing, a best value should be selected by considering the channel characteristics, vegetation growth, bed roughness among many other factors.

Another positive conclusion of this work is to point out that the water level-discharge relation parameters are more important than design rainfall parameters and design flood parameters. Thus, it is necessary to focus on the study of water level-discharge relation parameters, improving the accuracy of the RT value.
The Morris-Sobol Two-layer Progressive Model (M-STPM) proposed in this paper can provide a reference for the parameter value of the RT calculation of flash flood and lay a theoretical foundation for further analysis of the RT error. In addition, the proposed model can be applied to other RT calculation methods.

In this study, we discuss only the WL-DIM in the RT calculation. The application of the proposed model to different RT calculation methods or even other fields to identify sensitive parameters and provide the reference for the parameter value is a further line of research.

\section{ACKNOWLEDGEMENTS}

This study was supported by the China Institute of Water Resources and Hydropower Research, the Natural Sciences Foundation of China (51779229, 51509089, 51579101) and Distinguished Young Scholar of Science and Technology Innovation (184100510014). The authors wish to express deep thanks to the anonymous reviewers for their review.

\section{REFERENCES}

Amiri M., Arabhosseini A., Kianmehr M.H., Mehrjerdi M.Z. and Mirsaeedghazi H. (2017). Environmental impact assessment of total alkaloid extracted from the Atropa belladonna L. using LCA. Geology, Ecology, and Landscape. 1(4), 259-263.

Aziz N.I.H.A. and Hanafiah M.M. (2017). The Potential of Palm Oil Mill Effluent (POME) As A Renewable Energy Source. Acta Scientifica Malaysia. 1(2), 09-11.

Beven K. and Binley A. (1992). The future of distributed models: model calibration and uncertainty prediction. Hydrol. Proces. 6 (3), 279-298.

Francos A., Elorza F.J. and Bouraoui F. (2003). Sensitivity analysis of distributed environmental simulation models: understanding the model behaviour in hydrological studies at the catchment scale. Reliability engineering and system safety. 79 (2), 205-218.

Gao W., Wang Y., Basavanagoud B. and Jamil M.K. (2017). Characteristics studies of molecular structures in drugs. Saudi Pharmaceutical Journal. 25 (4), 580-586.

Gascón E., Laviola S., Merino A. and Miglietta M.M. (2016). Analysis of a localized flash-flood event over the central Mediterranean. Atmos Res. 182, 256-268.

Georgakakos K.P. (2006). Analytical results for operational flash flood guidance. J Hydrol. 317, 81-103. 
Ghafar F., Nazrin N.N., Salleh M.R.M., Hadi N.N., Ahmad N., Hamzah A.A., Yusof Z.A.M. and Azman I.N. (2017). Total phenolic content and total flavonoid content in moringa oleifera seed. Science Heritage Journal. 1(1), 23-25.

Griensven A.V., Meixner T. and Grunwald S. (2006). A global sensitivity analysis tool for the parameters of multi-variable catchment models. J. Hydrol. 324, 10-23.

Hapuarachchi H.A.P., Wang Q.J. and Pagano T.C. (2011). A review of advances in flash flood forecasting. Hydrol Process. 25 (18), 2771-2784.

Ismail H. and Hanafiah M.M. (2017). Management of End-Of-Life Electrical and Electronic Products: The Challenges and The Potential Solutions for Management Enhancement in Developing Countries Context. Acta Scientifica Malaysia. 1(2), 05-08.

Kim N.Y., Jeon E.J., Jung S.H., Ahn S.J., Park M.A. and Seo J.S. (2018). Gene expression profiling and expression analysis of freshwater shrimp (Neocaridina denticulata denticulata) using expressed sequence tags and short-term exposure to copper. Journal of Environmental Biology. 39 (1), 51-57.

Kylili A., Fokaides P.A., Ioannides A. and Kalogirou S. (2018). Environmental assessment of solar thermal systems for the industrial sector. Journal of Cleaner Production. 176, 99-109.

Lenhart T., Eckhardt K., Fohrer N. and Frede H.G. (2002). Comparison of two different approaches of sensitivity analysis. Phys. Chem. Earth. 27, 645-654.

Li C.Z. and Guo L. (2013). Methods of rainfall indicator for flash flood. China Flood \& Drought Management. 23 (6), 23-28.

Ma J.M., Tan X.M. and Zhang N.Q. (2010). lood management and flood warning system in China. Irrigation and drainage. 59, 17-22.

Morris M.D. (1991). Factorial sampling plans for preliminary computational experiments. Technometrics. 33 (2), 161-174.

Norbiato D., Borga M. and Esposti S.D. (2008). Flash flood warning based on rainfall thresholds and soil moisture conditions: An assessment for gauged and ungauged basins. J. Hydrol. 362, 274-290.

NWS. 2016. National Weather Service glossary. http:// w1.weather.gov/glossary/index.php

Pina-Garcia F., Pereda-Garcia R., de Luis-Ruiz J.M., Perez-Alvarez R. and Husillos-Rodriguez R. (2016). Determination of geometry and measurement of Maritime-Terrestrial lines by means of fractals: Application to the coast of cantabria (Spain). Journal of Coastal Research. 32 (5), 1174-1183.

Qu C., Wen-Bin D. and Yun G. (2017). Russia Forest Resource Management. Malaysian Journal of Sustainable Agriculture. 1(2), 12-14.
Reed S., Schaake J. and Zhang Z. (2007). A distributed hydrologic model and threshold frequency-based method for flash flood forecasting at ungauged locations. J. Hydrol. 337 (3-4), 402-420.

Rusanow A.V., Lampart P., Pashchenko N.V. and Rusanov R.A. (2016). Modelling 3d steam turbine flow using thermodynamic properties of steam iapws-95. Polish Maritime Research. 23 (1), 61-67.

Saltelli A. and Annoni P. (2010). How to avoid a perfunctory sensitivity analysis. Environmental Modelling and Software. 25 (12), 1508-1517.

Saltelli A., Ratto M., Tarantola S. and Campolongo F. (2005). Sensitivity analysis for chemical models. Chem. Rev. 105 (7), 2811-2828.

Saltelli A., Tarantola S. and Chan K.P.S. (1999). A quantitative model-independent method for global sensitivity analysis of model output. Technometrics, 41 (1), 39-56.

Shamsudin N.H., Wong C.F., Rahman N.Z.A. and Ali M.S.M. (2017). Tight repression of elastase strain K overexpression by Pt7 (A1/O4/O3) shuttle expression system. Science Heritage Journal. 1(1), 20-22.

Shen Y., Zhao N., Xia M. and Du X. (2017). A deep qlearning network for ship stowage planning problem. Polish Maritime Research. 24 (SI), 102-109.

Shin M.J., Guillaume J.H.A., Croke B.F.W. and Jakeman A.J. (2013). Addressing ten questions about conceptual rainfall-runoff models with global sensitivity analyses in R. J. Hydrol. 503, 135-152.

Sobol I.M. (1993). Sensitivity analysis for non-linear mathematical models. Mathematical Modelling and Computational Experiment, 1 (4), 407-414.

Song M.D., Feng H., Li Z.P. and Gao J.E. (2014). Global sensitivity analyses of Dssat-Ceres-Wheat model using Morris and EFAST methods. Transactions of the Chinese Society for Agricultural Machinery. 45 (10), 124-131.

Song X.M., Zhang J.Y. and Zhan C.S. (2015). Global sensitivity analysis in hydrological modelling: review of concepts, methods, theoretical framework, and applications. J. Hydrol., 523, 739-757.

Tan M.H., Yao J.J. and Zhang Z. (2015). Analysis and application of sensitivity of water quality parameter based on SWMM of Morris. Journal of Water Resources \& Water Engineering. 26 (6), 117-122.

Tan P.F., Hanafiah M.M., Mokhtar M.B. and Harun S.N. (2017). Rainwater Harvesting System: Low Awareness Level Among University Students in a High Rainfall Tropical Country. Malaysian Journal of Sustainable Agriculture. 1(2), 09-11.

Tariq W., Hussain S.Q., Nasir A., Tayyab N., Gillani S.H. and Rafiq A. (2017). Experimental Study on Strength and Durability of Cement and Concrete By Partial 
Replacement Of Fine Aggegate With Fly Ash. Earth Sciences Pakistan. 1(2), 07-11.

Venutelli M. (2005). A Constitutive Explanation of Manning's Formula. Meccanica, 40 (3), 281-289.

Villarini G., Krajewski W.F. and Ntelekos A.A. (2010). Towards probabilistic forecasting of flash floods: The combined effects of uncertainty in radar-rainfall and flash flood guidance. J Hydrol. 394, 275-284.

Wan F., Yuan W.L. and Zhou J. (2017). Derivation of Trilevel programming model for multi-reservoir optimal operation in inter-basin transfer-diversion-supply project. Water Resour. Manage. 31, 479-494.

Wang J.D., Gu T.F. and Xu Y.J. (2017). Field tests of expansive soil embankment slope deformation under the effect of the rainfall evaporation cycle. Applied Ecology and Environmental Research. 15 (3), 343-357.
Xu J.H., Shu H., Jiang H.N. and Dong L. (2012). Sobol' sensitivity analysis of parameters in the common land model for simulation of water and energy fluxes. Earth. Sci. Inform. 5, 167-179.

Yasin H., Usman M., Rashid H., Nasir A. and Randhawa I.A. (2017). Alternative Approaches for Solid Waste Management: A Case Study in Faisalabad Pakistan. Earth Sciences Pakistan. 1(2), 04-06.

Yun G., Williams S. and Wenbin D. (2017). Water Management of The Mekong River. Malaysian Journal of Sustainable Agriculture. 1(2), 15-17.

Zhang Y. (2014). The study on global sensitivity analysis and dynamic metamodel of multiple-parameters nonlinear system. Dissertation, Hu Nan university. 